\title{
Research and Development of Motivation in the Structure of Professional Strategy of a Student-Future Psychologist
}

\author{
Yulia Vladimirovna Vardanyan*, Lyudmila Valerjevna Vardanyan \\ and Ekaterina Aleksandrovna Lezhneva
}

\author{
Mordovian State Pedagogical Institute Named after M. E. Evsevyev, Russia.
}

DOI: http://dx.doi.org/10.13005/bbra/1967

(Received: 01 October 2015; accepted: 19 November 2015)

\begin{abstract}
The problem stated in the article is important today because of increasing demands for qualitative solution to professional tasks by psychologist. It largely depends on formation of his constructive professional strategy. The paper aims to prove (using reliable experimental data) that motivation is the essential component of professional strategy of a student - future psychologist. It encourages, directs, regulates his academic and professional activity, defines the trajectory of professional and personal development. The practical significance of the article consists in the fact that the suggested program for development of motivation in the structure of students' professional strategy can be used to solve the problems of professional and personal development of students - future psychologists.
\end{abstract}

Key words: Professional strategy, motive, motivation, professional motivation, achievement motivation, student - future psychologist.

In the problem of motivation, which remains the most difficult in psychological science, special attention is given to the study of motives for different types of activity as they affect the productivity of the activity, manage it, form special attitude to it. Of considerable interest is the detection of motives of students - future psychologists, as they are intended to solve a wide range of problems of modern society (development of cognitive sphere and personal resources of different categories of people, their interpersonal relations, communication and creativity).

According to the analysis great attention was paid to "the study of psychological safety as a general problem of professional development of students of different faculties, qualitative solution to which becomes the leading factor in the

\footnotetext{
* To whom all correspondence should be addressed. E-mail: julia_vardanyan@mail.ru
}

implementation and development of their professional strategy" (Vardanyan Y. \& Vardanyan L., 2015, p. 240). In this context the technologies to actualize the achievement motive and reduce the action of the failure avoiding motive (enhancing psychological safety and positively influence the development of student's professional strategy) were considered (Vardanyan et al., 2014a).

During professional activity, it is important for psychologist to be internally motivated to carry out the professional functions qualitatively, to strive for success and effectiveness. However, several studies show that a significant part of students - future psychologists is characterized by weak formation of motivation for academic and professional activity, uncertainty of professional plans, vague attitude to the profession of "Educational Psychologist", lack of skills to design and implement the trajectory of professional and personal development (Berdnikova \& Vindeker, 2014; Dubrovina, 2012, Loginova, 2011, etc.). Thus, lack of academic and professional motivation "hampers the formation of 
significant motivation to master the profession and has a negative impact on the success of learning" (Loginova, 2011, p. 111). Strengthening of a tendency "towards rapid devaluation of the achieved level of professional competencies, which is no longer sufficient for qualitative solution to emerging professional tasks" (Vardanyan et al., 2014a, p. 852) leads to the feeling of loss of success, reduction in self-esteem of general and professional achievements and increase in helplessness. Motivation for academic and professional activity is an essential component of constructive professional strategy that contributes to impulse, direction and regulation of the process of professional and personal self-development of a student - future psychologist. Therefore, it is necessary to form it at a higher educational institution. Under student's professional strategy we understand the plan for mastering the future professional activity and its subsequent implementation. This plan sets the trajectory of professional and personal formation and largely depends on active/inactive/counteractive motivation during the implementation of the plan.

\section{Literature review}

The term "motivation" is used in two ways: as referring to the system of factors determining the behaviour (needs, motives, goals, intentions) and as a process that encourages and supports the personal activity at a particular level. In a Large Psychological Dictionary there is the following definition: "Motivation - 1) the cumulative effect of many internal and external factors (motivational factors), which become apparent in the form of inducement to behave with a certain direction, intensity, persistence; 2) a set of motivational factors, including the organic needs (necessities), their subjective reflection (drives), perceived and represented means of meeting the needs (motives, goals, incentives), emotions etc., which provide the activation, direction and sustainability of behaviour and activity" (Large Psychological..., 2009, p. 372). According to Aseev (1976), motivational sphere "includes all kinds of inducements: motives, needs, interests, aspirations, goals, appetence, motivational installations or dispositions, ideals etc. (p. 7). The set of motives and their certain location form the motivational system, which can be expressed by various versions - academic motivation, achievement motivation, avoiding failure motivation etc. (Meshkov \& Yashkova, 2014). The motives for activity vary with strength, content, origin and place in the hierarchy of the whole system of motives, induce and regulate the execution of activity. According to several researchers, achievement motivation has a positive impact on students' progress and, consequently, on their activity and personal self-development (Alderman, 2004; Elliot \& Thrash, 2001; Price \& Kadi-Hanifi, 2011; Seifert, 2004, Trumbull \& Rothstein, 2011). Because students form selfconcepts, values, and beliefs about their abilities at a young age, the development of early academic motivation has significant implications for later academic careers (Kulwinder, 2011, p. 165). To achieve a certain goal, students should be motivated and they should have "rudimentary conceptual and procedural knowledge of how to attain that goal" (Westbroek et al., p. 603). Motivation of students to get knowledge contributes to systematic character of academic activity. So, such students are characterized by purposefulness, strong will, etc. Targeting of motivation to get a profession leads to the fact that most of the students become selective towards the proposed educational courses. Motivation of students to get a diploma is considered to be undesirable from the standpoint of preparation of future specialists with a higher education, as it doesn't contribute to their targeting at the learning process (Iljin, 2011).

Most authors distinguish internal and external motives in the structure of motivation for academic and professional activity. Research carried out in the framework of the paradigm of internal / external motivation suggests that the internal academic motivation is associated with greater persistence, high achievements, manifestations of creativity, more favorable perceptions of one's academic abilities and with low level of anxiety (Gordeeva et al., 2013; Gordeeva, 2014; Lyah T. \& Lyah M., 2012; Zanyuk, 2001). The internal motive has stronger and more significant impact on the success of academic and professional activity, as an incentive to carry out the activity comes from the activity itself, its features and interest to it.

While analyzing the structure of academic and professional motivation it is interesting to 
divide it according to emotional modality into positive and negative. The first form of inducements appears mainly in relatively favorable circumstances (absence of external or internal obstacles), the second - in unfavorable circumstances (Aseev, 1976). Emotions and convictions are believed to cause different models of behavior, such as striving for excellence, avoidance of failure, learned helplessness and passive aggression (Seifert, 2004).

Our previous studies (Vardanyan et al., 2014a; Vardanyan et al., 2014b; Lezhneva, 2014) have proved the positive effect of achievement motivation on academic and professional activity, as it stimulates a man to search for such situations in which the motivation becomes a necessity for professional achievements and is concretized in them. While mastering the profession, future psychologist learns how to make a choice, make decisions and take responsibility, learn from successes and failures, motivate oneself to interact and have a result.

Motivational sphere is quite dynamic and can be easily changed (Zanyuk, 2001). It is important (from the early stages of professional development in the course of university training) to conduct a specially organized work on formation of motives for understanding the purpose of profession, motives for professional activity and motives for manifestation of personality in the profession, constituting in their totality the motivation for professional activity (Matsakova, 2011).

\section{MATERIALSAND METHODS}

During the research the following methods were used: a) organizational methods (comparative, longitudinal, analysis of scientific literature); b) empirical methods (psychodiagnostic - "Study of students' academic motivation" by Ilyina (Practicum..., pp. 491-493), “Motivation for professional work" by Zamfir (modified by Rean) (Rean, 2006, pp. 84-86), "Measurement of achievement motivation” by Mehrabian (Practicum..., pp. 509-512); analysis of the products of activity; formative experiment); c) methods of mathematical and statistical data processing (Mann-Whitney U test) (Sidorenko, 2003, pp. 4959).
Experimental work was carried out at the Faculty of Psychology and Defectology of Mordovian State Pedagogical Institute named after M. E. Evsevyev. 40 students participated in it were divided into equal experimental (EG) and control (CG) groups. The study consists of four stages: 1 ) at the preparatory stage the state of the problem in psychological theory and practice was analyzed, research methods were selected, the base for experimental work was defined; 2) at the ascertaining stage the motives for students' academic and professional activity were studied, experimental and control groups were formed, the program for formation of the mentioned types of motives was worked out; 3 ) at the formative stage the program for formation of the motives for students - future psychologists' academic and professional activity during the study of psychopedagogical disciplines was implemented; 4 ) at the control stage the final study of the motives for students' academic and professional activity was conducted, the results of the study were systematized, interpreted and summarized, theoretical conclusions were refined, the processing and registration of the results was done.

\section{RESULTS AND DISCUSSION}

We consider the academic motives, motives for professional work and achievement motives to be the leading motives for academic and professional activity of students - future psychologists. During the study we tested the validity of the following hypothesis: students' professional strategy is more constructive if in its structure, the following motives will be dominated: by direction - internal, by modality - positive, by content - "mastering the profession" and "desire to succeed".

At the ascertaining stage the initial level of motivation for academic and professional activity was examined. There were used such methods as "Study of students' academic motivation" by Ilyina, "Motivation for professional work" by Zamfir (modified by Rean), "Measurement of achievement motivation” by Mehrabian (table 1).

The data analysis shows, that for the majority of students the significant academic motives are "Getting a diploma" ( $45 \%$ of students of experimental group and $40 \%$ of students of 
control group) and "Acquisition of knowledge" ( $40 \%$ of students of control group). Typical motives for professional activity are external motives: positive ( $40 \%$ of students of experimental and control groups) and negative ( $40 \%$ of students of experimental and control groups). Only a small amount of students of experimental and control groups is characterized by an "internal motive", a "motive for mastering the profession" and the "desire to succeed" in academic and professional activity. For the majority of students the dominant motive is the "desire to avoid failure" (80\% of students of experimental group and $70 \%$ of students of control group). The analysis of data obtained with the help of Mann-Whitney U test showed that there are no significant differences in value of the tested motives between students of experimental and control groups. Thus, the data show the need to form purposefully those kinds of motives that underlie the constructive professional strategy.

At the formative stage, the program, including a system of targeted developmental tasks was worked out. It was used to form purposefully the motives for academic and professional activity during the study of psycho-pedagogical disciplines ("General and Experimental Psychology”, “Adaptative Training”, "PsychoPedagogical Practicum”). This program was realized with the students of experimental group at junior courses of professional education. While mastering the discipline "General and Experimental Psychology" the basic scientific knowledge about the need-motivational and valuable spheres of personality and its orientation were formed among students. Besides the skills to carry out a self

Table 1. Study of motivation for academic and professional activity of students - future psychologists at the ascertaining stage

\begin{tabular}{lllrr}
\hline \multirow{2}{*}{ Types of motives } & Indicator & \multicolumn{2}{c}{ Respondents (in \%) } & \multirow{2}{*}{ Value of } \\
& & EG & CG & $\mathrm{U}_{\text {emp. }}$ \\
\hline Academic motives & Acquisition of knowledge & 35 & 40 & 198 \\
& Mastering the profession & 20 & 20 & 142 \\
Motives for professional activity & Getting a diploma & 45 & 40 & 162 \\
& Internal & 20 & 20 & 152 \\
& External positive & 40 & 40 & 156 \\
Achievement motives & External negative & 40 & 40 & 167 \\
& Desire to avoid failure & 80 & 70 & 187 \\
\hline
\end{tabular}

Notations: $\mathrm{p} \leq 0,05^{*}(138) ; \mathrm{p} \leq 0,01^{* *}(114)$

Table 2. Change in motivation for academic and professional activity of students - future psychologists during the study

\begin{tabular}{|c|c|c|c|c|c|c|}
\hline \multirow[t]{3}{*}{ Types of motives } & \multirow[t]{3}{*}{ Indicator } & \multicolumn{4}{|c|}{ Respondents (in \%) at the stage } & \multirow{3}{*}{$\begin{array}{c}\text { Value of } \\
\mathrm{U}_{\text {emp. }}\end{array}$} \\
\hline & & \multicolumn{2}{|c|}{ Ascertaining } & \multicolumn{2}{|c|}{ Control } & \\
\hline & & EG & CG & EG & CG & \\
\hline \multirow[t]{3}{*}{ Academic motives } & Acquisition of knowledge & 35 & 40 & 35 & 50 & $130^{*}$ \\
\hline & Mastering the profession & 20 & 20 & 55 & 25 & $81.5^{* *}$ \\
\hline & Getting a diploma & 45 & 40 & 10 & 25 & $107.5^{* *}$ \\
\hline \multirow{3}{*}{$\begin{array}{l}\text { Motives for professional } \\
\text { activity }\end{array}$} & Internal & 20 & 20 & 55 & 25 & $99^{* *}$ \\
\hline & External positive & 40 & 40 & 35 & 50 & $126^{*}$ \\
\hline & External negative & 40 & 40 & 10 & 25 & $123.5^{*}$ \\
\hline \multirow[t]{2}{*}{ Achievement motives } & Desire to avoid failure & 80 & 70 & 55 & 60 & $133^{*}$ \\
\hline & Desire to succeed & 20 & 30 & 45 & 40 & \\
\hline
\end{tabular}

Notations: $\mathrm{p} \leq 0,05^{*}(138) ; \mathrm{p} \leq 0,01^{* *}(114)$ 
diagnosis and use the results for professional and personal self-development were developed. Organization of independent students' work involved the following targeted developmental tasks: writing a compositions "The world of a person and his motives", preparation of psychological portrait "My professional needs and motives", writing an essay "The influence of success and failure on academic and professional activity”, analysis of motives for person's actions and activity in different life situations, selection of psychodiagnostic methods to study the needmotivational sphere etc.

While studying the discipline "Adaptative Training” the greatest efficiency in the formation of motives for academic and professional activity was achieved through the system of the following targeted developmental tasks: writing a composition "Why did I want to become a psychologist", writing an essay "The motives to choose the profession of psychologist", performance of a creative project "My professional goals", selection of examples of the behavior under the influence of achievement motivation / failure avoiding motivation, etc.

In the process of mastering the discipline "Psycho-Pedagogical Practicum" students worked out active professional and motivational-value attitude towards the future profession. Taking into account that the "effects of psychological defense mechanisms in the context of professional strategy development can reduce the adequacy of behavior" (Vardanyan et al., 2014c, p. 362) great attention was paid to prevent such a result. Students did the following targeted developmental tasks: writing a composition "Motives for my behavior and activity", performance of a creative project "What a psychologist I will be in 5 years?", doing various exercises during the training work ("I am a successful professional”, "Getting a job”, "Interview from the Future"), participation in the discussion "Influence of various motives on professional activity of a person" etc.

At the fourth stage of the study the effectiveness of the program was evaluated by comparing students' dominant academic motives and motives for professional work at ascertaining and control stages of the study (Table 2).

Let's consider the changes in the motives for academic and professional activity. Data obtained using the method "Study of students' academic motivation" by Ilyina, showed the changes in prevailing academic motive: in experimental group at ascertaining stage, among the majority of students the significant motive was "getting a diploma" (45\%) and at the control stage "mastering the profession” (55\%). Among students of control group at ascertaining stage the equally significant academic motives were "acquisition of knowledge" (40\%) and "getting a diploma" (40\%) and at the control stage "acquisition of knowledge" (50\%). Analysis of obtained data using MannWhitney $U$ test revealed significant differences in value of investigated motives among students of experimental and control groups.

Analysis of individual data obtained using the method "Motivation for professional activity" by Zamfir (modified by Rean) showed the important changes in the significance of motives for professional activity in experimental group: in comparison with ascertains stage, the number of students with internal motive has increased (from 20\% to 55\%) and the number of students with external negative motive has decreased (from $40 \%$ to $10 \%$ ). The majority of students of experimental group (55\%) are characterized by internal motive of professional activity. That means that the activity itself, the satisfaction from the process and the result of the work and the possibility for the most complete selfrealization in that particular activity are important for them. The majority of students of control group showed external positive motive (motives of social prestige and advancement, earning money, respect from others, etc.). Statistically significant differences among data obtained in experimental and control groups (concerning the expression of motives for professional activity) were revealed.

The study of achievement motivation showed that in experimental group the number of students striving to avoid failure has significantly decreased (from $80 \%$ to $55 \%$ ), and the number of students, characterized by the desire to succeed has increased (from 20\% to 45\%). In the control group, these changes are minor (in comparison with the experimental group) and are the following: the number of students with the predominant motive to succeed increased (from 30\% to $40 \%$ ) and the number of students with the avoiding failure motive decreased (from $70 \%$ to $60 \%$ ). 
Statistical significance of the obtained changes, evaluating by means of Mann-Whitney U test, showed the differences between the data concerning the indicators of students' achievement motivation (desire to succeed and desire to avoid failure) in experimental and control groups at the control stage of the study.

\section{CONCLUSIONS}

Literature review on the investigated problem showed that the most significant motives underlying the formation of a person's professional strategy are academic motives, motives for professional activity and achievement motives. The data of ascertaining stage of the study showed weak formation of those kinds of motives (internal, mastering the profession, motive to succeed) that are necessary for successful implementation of academic and professional activity. It is found that the created program for formation of academic and professional motivation, consists of a system of targeted developmental tasks, is rather effective and allows the following:

1) for a teacher - to organize the motivational equipment of the training of future psychologists purposefully, to improved their motivational and valuable sphere;

for a student - to master the knowledge about motivation, types of motives, motivation for professional activity and its components, conditions for their development; to manage one's own professional and personal development and solve professional problems qualitatively.

The article may be useful in a practical way for teachers of psychological and psychopedagogical departments to form scientific and methodological materials and recommendations, for heads of organizations to select the staff, for students and practicing psychologists for selfeducation and self-development.

According to the results of the study we can identify a number of scientific problems and promising areas for further consideration: deepening and broadening of some points contained in the article related to formation of motivation for academic and professional activity in the study of non-psychological disciplines, psychological support of a person's activity during development of a program and scientific and methodical maintenance of the process of selfstudy and self-development of constructive professional strategy.

\section{ACKNOWLEDGMENTS}

This study was carried out with the financial support of the Department of Education and Science of the Russian Federation on the task 1 2014/356 for making the state works in the field of scientific activity in the basic part of the State task for Federal State Budget Educational Institution of Higher Professional Education "Mordovian State Pedagogical Institute named after M. E. Evsevyev", the project "Psychological safety as a factor of development and implementation of a personality's professional strategy" (project code 2041).

\section{REFERENCES}

1. Alderman, M. K. Motivation for Achievement: Possibilities for Teaching and Learning. Mahwah, N. J. 2004; 354.

2. Aseev, V. G. Motivation for Behavior and Personality Development. Moscow. 1976; 184.

3. Berdnikova, D. V. \& Vindeker, O. S. Study of Interrelation of Students' Achievement Motivation and Academic Motivation. Izvestiya of the Ural Federal University, Series 3: Social Sciences, 2014; 125(1): 145-152.

4. Dubrovina, I. V. Professional Training of Practical Educational Psychologist. Psychological Science and Education, 2012; 1: 90-100.

5. Elliot, A. J. \& Thrash, T. M. Achievement Goals and the Hierarchical Model of Achievement Motivation. Educational Psychology Review, 2001; 13(2): 139-156.

6. Gordeeva, N. O., Sychov, O. A. \& Osin, E. N. Students' Internal and External Academic Motivation: its Sources and Impact on Psychological Well-being. Issues of psychology, 2013; 1: 35-45.

7. Gordeeva, T. O. The Basic Types of Activity Motivation: Requirement Model. Bulletin of Moscow University, Series 14: Psychology, 2014; 3: 63-78.

8. Ilyn, E. P. Motivation and motives. St. Petersburg. 2011; 512.

9. Kulwinder, S. Study of Achievement Motivation in Relation to Academic Achievement of 
Students. International Journal of Educational Planning \& Administration, 2011; 1(2): 161-171

10. Large Psychological Dictionary. St. Petersburg. 2009; 372.

11. Lezhneva, E. A. Influence of Educational and Professional motivation on the Development of Professional Strategy of Bachelor of Psychopedagogical Education. Kazan Science, 2014; 12: 254-256.

12. Loginova, N. G. Study of Professional Significance of Student-Bachelor's Psychological Motivation. The Humanities and education, 2011; 1(5): 109-111.

13. Lyah, T. I. \& Lyah, M. V. Motivational and Meaningful Aspects of Future Psychologists' Professional Training. Tula. 2011; 96.

14. Matsakova, N. V. Features of Academic and Professional Motivation of the Future Psychologist. Theory and practice of social development, 2011; 3: 165-166.

15. Meshkov, N. I. \& Yashkova, A. N. The Problem of Motivation in Psychological Science. The Humanities and education, 2014; 4(20): 50-54.

16. Practicum on Developmental Psychology. St. Petersburg. 2010; 694 p.

17. Price, F. \& Kadi-Hanifi, K. E-motivation! The Role of Popular Technology in Student Motivation and Retention. Research in PostCompulsory Education, 2011; 16(2): 173-187. doi:http://dx.doi.org/10.1080/13596748.2011. 575278

18. Rean, A. A. Psychology and Psychodiagnostic of Personality: Theory, Research Methods, Practicum. St. Petersburg. 2006; 84-86.

19. Seifert, T. Understanding Student Motivation. Educational Research, 2004; 46(2): 137-149. doi:http://dx.doi.org/10.1080/00131880420002
22421

20. Sidorenko, E. V. Methods of Mathematical Processing in Psychology. St. Petersburg. 2003; 350.

21. Trumbull, E. \& Rothstein, F. C. The Intersection of Culture and Achievement Motivation. School Community Journal, 2011; 21(2). http:// www.questia.com/read/1P3-2546619391/theintersection-of-culture-and-achievementmotivation

22. Vardanyan Y. V. \& Vardanyan L. V. Development of professional strategy of a future coach in the context of psychological safety in sport. Ciencia e Tecnica Vitivinicola, 2015; 30(10): 235-245.

23. Vardanyan, Y. V., Vardanyan, L. V. \& Lezhneva E. A. Achievement Motivation in the Context of Psychological Safety as a Factor of Development of Student's Professional Strategy. Life Science journal, 2014a; 11(10): 851-857.

24. Vardanyan, Y. V., Vardanyan, L. V. \& Lezhneva, E. A. Influence of Training in Psychological Safety on Development of Motivational Basis of Student's Professional Strategy. Ciencia e Tecnica Vitivinicola, 2014b; 29(10): 2-11.

25. Vardanyan, Y. V., Vardanyan, L. V. \& Dergunova, A. V. Psychological Defense and Safety in the Context of Development of Student's Professional Strategy. Biosciences Biotechnology Research Asia, 2014c; 11: 357-364.

26. Westbroek, H., Klaassen, K., Bulte, A. \& Pilot, A. Providing Students with a Sense of Purpose by Adapting a Professional Practice. International Journal of Science Education, 2010; 32(5): 603-627. doi:http://dx.doi.org/10.1080/ 09500690902721699

27. Zanyuk, S. Psychology of Motivation. Kiev. 2001; 352. 